\title{
A POÉTICA HIPER-REGIONAL DO “SERTÃO” DE ROSA NO “CHÃO” DE SARAMAGO
}

\section{THE HYPER-REGIONAL POETIC OF THE "SERTÃO" OF ROSA IN THE "GROUND" OF SARAMAGO}

\author{
Peterson Martins Alves Araújo
}

Universidade de Pernambuco

\begin{abstract}
RESUMO
O objetivo deste artigo é apresentar a verificação de que a estética regionalista não foi extinta das literaturas de língua portuguesa, mas se transformou em uma nova poética denominada hiperregional (ou estética hiper-regionalista), tal como aponta Marli Fantini Scarpelli (2003). A metodologia utilizada para a verificação dessa poética (ou estética) foi a da Literatura Comparada - tomando como referências iniciais as obras Grande sertão: veredas de Guimarães Rosa e o Romance d'A Pedra do Reino de Ariano Suassuna para se verificar a presença de características semelhantes na obra Levantado do Chão de José Saramago. Nosso trabalho parte, inicialmente, das verificações de Antonio Candido em seu texto "Literatura e subdesenvolvimento" (CANDIDO, 1989), para se guiar principalmente pelas teorias de gênero literário e cronotopo de BAKHTIN (1998) e do neobarroquismo de Josina Nunes Drumond (2008). Com a finalidade de contribuir para a ampliação dos estudos literários ao fato regional que adquire caracteres universais - proposta
\end{abstract} maior dessa poética.

PALAVRAS-CHAVE: Hiper-regionalismo; Cronotopo; Guimarães Rosa; José Saramago.

\begin{abstract}
The aim of this article is to present the verification that regionalist aesthetics were not extinguished in Portuguese-language literatures, but became a new hyper-regional poetics (or byper-regionalist aesthetics), as pointed out by Marli Fantini Scarpelli (2003). The methodology used to verify this poetics (or aesthetics) was that of Comparative Literature - taking as initial references the works The Devil to Pay in the Backlands by Guimarães Rosa and the Romance of the Stone of the Kingdom by Ariano Suassuna to verify the presence of similar characteristics in the novel Raised from the ground by José Saramago. Our paper begins with Antonio Candido's verifications in his text "Literature and underdevelopment" (CANDIDO, 1989), to be guided mainly by the theories of literary genre and chronotope of Bakhtin (1998) and the neo-baroquism of Josina Nunes Drumond (2008). We aim to contribute to the expansion of literary studies to the regional fact that acquires universal features - the major proposal of this poetic.
\end{abstract}

KEYWORDS: Hyper-regionalism; Chronotope; Guimarães Rosa; José Saramago.

\section{INTRODUÇÃO}

O percurso pela análise do universo ficcional de Guimarães Rosa e José Saramago, respectivamente em suas obras Grande sertão: veredas e Levantado do Chão, inicia-se pela constatação de uma nova poética que redimensiona as perspectivas anteriores no desenvolvimento da

\footnotetext{
1 Doutor em Estudos da Linguagem (Área de concentração: Literatura Comparada) do PPGEL/CCHLA da Universidade Federal do Rio Grande do Norte (UFRN). Professor Adjunto da UPE. Vice-Líder do Grupo de Pesquisa "Itinerários Interdisciplinares de Estudos sobre o Imaginário" (ITESI). E-mail: peterson.martins@upe.br
}

Revista do GELNE, Natal/RN, Vol. 20 - Número 1: p. 285-295. 2018 
temática regional. Essa constatação foi obtida mediante uma análise comparativa em pesquisa realizada sobre a convergência de diversas características estéticas entre as obras Grande sertão de Guimarães Rosa e o Romance d'A Pedra do Reino de Ariano Suassuna que culminaram na elaboração de uma tese, defendida na UFRN em junho de 2012, com o título de Os Sertões Infinitos da Estética Hiper-regional de Guimarães Rosa e Ariano Suassuna.

O marco inicial, indubitavelmente, foi o ensaio Literatura e Subdesenvolvimento de Antonio Candido, publicado inicialmente, na França, em 1970, onde o crítico literário brasileiro aponta que o desenvolvimento da consciência do subdesenvolvimento na literatura apenas foi adquirido a partir do reconhecimento do "outro" em sua condição marginalizada; e, essa percepção da alteridade, por sua vez, foi desenvolvida, na literatura brasileira, nas várias fases do regionalismo.

Segundo o ensaio de Candido, a Literatura Brasileira, teria passado por três fases principais: o "regionalismo pitoresco" (ou romântico), o "regionalismo problemático" (em referência ao romance regionalista de 1930) e o "super-regionalismo". Nessa última fase da temática regional apontada por Candido, encontramos o "mote" principal para perceber a convergência estética que, inicialmente, analisamos entre os romances de Rosa e Suassuna, mas que, a cada momento, percebemos em diversas obras da literatura brasileira, latino-americana, portuguesa ( $\mathrm{e}$, porque não dizer, da literatura mundial) apresentam, dentro de suas especificidades, características semelhantes.

Sinteticamente, observa-se que, hoje, elas não buscam somente uma definição dos marginalizados (ou excluídos), mas referenciar o próprio esforço identitário de se definirem dentro do contexto fragmentário da hipermodernidade ou do hiper-capitalismo que nós vivemos. Segundo Gilles Lipovetsky (2011, p. 31-32) que estabelece novas relações socioeconômicas e culturais a partir da consciência do "estilhaçamento" do ser e de todas as suas outras relações provocada pela individualização da existência amplificada pelo universo tecno-midiáticomercantil. Essa denominação de Lipovetsky para descrever o contexto socioeconômico na qual vivemos, hodiernamente, também será um dos fatores determinantes para a escolha do termo "hiper-regional", no lugar do "super-regionalismo" de Antonio Candido. Além da associação ao termo similar das artes plásticas, no qual o hiper-regional se refere a um movimento estético surgido na década de 60 (séc.XX) através das pinturas de Edward Hopper em que unia o surrealismo às representações realistas.

Apesar da definição dessa poética "hiper-regional", ter partido de algumas reflexões apontadas por Candido, percebemos, em Mikhail Bakhtin, importantes instrumentos de análise que foram chave na elucidação de diversos aspectos desenvolvidos por essa poética. Dentre esses elementos podem ser citados alguns: a constatação da importância do outro na construção de nosso próprio discurso; a quebra de uma visão hierárquica dos gêneros discursivos (e, por extensão, dos literários); a hibridização do discurso e gêneros; e a categoria de cronotópo aplicada aos estudos literários.

\section{As cores primárias da estética hiper-regional}

Basicamente, pode-se afirmar que a poética "hiper-regional" é uma estética contemporânea que surge a partir da junção do realismo com o surrealismo. Percebida como uma releitura da "cor local" em uma dimensão universal, o hiper-regional tem como proposta uma mitificação do ser, do espaço e do tempo sem perder a dimensão social atual. Isso é feito com o propósito de representar e fornecer respostas à identidade fragmentada do ser contemporâneo que (conforme, o conceito do "enraizamento dinâmico" de Michel Maffesoli em seu livro Sobre nomadismo: vagabundagens pós-modernas) deve-se abrir em uma perspectiva da alteridade. $\mathrm{O}$ "outro" ajuda a forjar tanto a nossa psiquê quanto o nosso discurso, tal como defende Bakhtin.

E, para a caracterização da poética "hiper-regional", partimos (como falamos anteriormente) da percepção de Candido em seu "super-regionalismo", que o delimita afirmando que tal estética surge, na Literatura Brasileira, a partir das experiências linguísticas e do estilo de

Revista do GELNE, Natal/RN, Vol. 20 - Número 1: p. 285-295. 2018 
Guimarães Rosa em seu romance Grande sertão: veredas publicado em 1956. Segundo Candido, essa obra de Rosa estabeleceu as seguintes características:

[...] o sentimentalismo e a retórica; nutrida de elementos não-realistas, como o absurdo, a magia das situações; ou de técnicas antinaturalistas, como o monólogo interior, a visão simultânea, o escorço, a elipse - ela implica não obstante em aproveitamento do que antes era a própria substância do nativismo, do exotismo e do documentário social. Isto levaria a propor a distinção de uma terceira fase, que se poderia (pensando em surrealismo, ou super-realismo) chamar de super-regionalista. (CANDIDO, 1989, p. 161-162).

Já na análise que realizamos, na tese supracitada, chegamos às seguintes características:

* a busca do equilíbrio entre o local e o universal; o rural e o urbano

* a junção de aspectos do realismo e do surrealismo;

* a hibridização do discurso romanesco;

* a presença da técnica do "redemoinho narrativo";

* a utilização de elementos (neo)barrocos;

* o efeito "matrioska" na composição da estrutura do romance;

* a mitificação do ser, espaço e tempo (Cronotopo do "Sertão");

* a fragmentação identitária dos narradores-protagonistas.

Dentre essas características, as que consideramos relevantes aos estudos literários contemporâneos, foram: a percepção da oscilação narrativa que denominamos "redemoinho narrativo" (em homenagem a Guimarães Rosa) e a "estrutura matrioska" do romance "hiperregional". E será sobre essas duas perspectivas que centrarei a análise comparativa entre Rosa e Saramago nos próximos tópicos.

\section{O redemoinho narrativo nas telas de Rosa e Saramago}

O primeiro ponto para podermos compreender as narrativas contemporâneas (e, em especial, a narrativa "hiper-regional") é a de que houve, entre os séculos XX e início do XXI, uma intensidade maior na fragmentação (ou diluição) dos gêneros literários. Sobre isso, especifica Haroldo de Campos ${ }^{2}$ que essa diluição dos gêneros ocorre também na quebra de suas "castas" entre o que seriam as formas literárias eruditas e populares, apontando, como início desse processo, a rebeldia estilística das criações literárias de Victor Hugo no romantismo francês.

Essa fragmentação dos gêneros literários também foi observada por Mikhail Bakhtin, sobretudo em suas obras Questões de literatura e estética: teoria do romance e Problemas da poética de Dostoiévski, onde se visualiza esse processo a partir da dissolução das formas arquitetônicas (ou primárias) dentro das formas composicionais (secundárias). Exemplificando melhor como seria essa composição, Bakhtin (1998, p. 24) fala que uma dessas principais formas composicionais seria o romance; e a sua forma arquitetônica seria a própria configuração do(s) narrador(es), o tipo das personagens, o caráter (que no drama podemos distinguir entre o trágico e o cômico), tal como a elaboração lírica ou prosaica da narrativa etc. Contudo, um pouco mais adiante em suas reflexões,

\footnotetext{
2 Nossa época tem assistido, justamente, ao reverso da medalha e à dissolução vertiginosa do estatuto dos gêneros, assim como o da sua compartimentação linguística. O Romantismo constituiu, nesse sentido, uma revolução contra o caráter predominantemente proibitivo das normas estéticas clássicas e se manifestou sobretudo - sempre segundo Mukarovsky, que focaliza em especial o exemplo francês -, no campo do léxico, onde vigia a discriminação entre palavras nobres (nobles) e baixas (bas), sendo estas últimas excluídas da linguagem-padrão. Contra essa segregação das palavras em 'castas', rebelou-se Victor Hugo, fazendo-se porta-voz das reinvindicações românticas, no poema Réponse a un Acte d'Accusation', no qual o poeta proclama ter colocado um bonnet rouge no velho dicionário. (CAMPOS, 1977, p. 10)
} 
chega a estabelecer também a possibilidade de outras formas composicionais estarem absorvidas dentro de uma macroforma (isto é, o gênero literário cujas características acabam predominando na identificação da forma literária), tal como o de um único romance que absorve dentro de si uma narrativa policial, um poema épico, uma prosa memorialista etc.

Daí que essa oscilação narrativa (ou "redemoinho narrativo") vem da consciência de que as formas híbridas não se estabelecem apenas nos gêneros, mas, sobretudo, no próprio discurso. $\mathrm{Na}$ compreensão bakhtiniana, o discurso não possui uma dimensão hierárquica, mas está sujeito a forças centralizadoras (centrípetas) e descentralizadoras (centrífugas). $\mathrm{Na}$ dimensão do romance hiper-regional, iremos ter, simultaneamente, a ação das duas forças: a força centrífuga típica do gênero romanesco e da força centrípeta pertinente ao gênero da poesia. Para sintetizar essa reflexão, elaborei um quadro comparativo em que tomamos a identificação dessas forças através da ideia de traços que tenderiam a aparecer mais $(+)$ e menos $(-)$ em cada gênero do discurso literário.

\begin{tabular}{|c|c|c|c|c|}
\hline \multirow{5}{*}{$\begin{array}{l}\text { GÊNEROS } \\
\text { DISCURSIVOS } \\
\text { LITERÁRIOS }\end{array}$} & \multirow{5}{*}{ 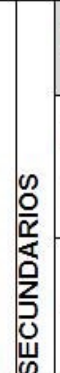 } & FORMA & AÇÄO DE FORÇAS & $\begin{array}{l}\text { PRESENÇA } \\
\text { VOZES }\end{array}$ \\
\hline & & \multirow{2}{*}{$\begin{array}{l}\text { PROSA } \\
\text { (Romance) }\end{array}$} & \multirow[t]{2}{*}{ Centrifuga } & $\begin{array}{l}\text { dialógico } \\
\text { (polifonia) (+) }\end{array}$ \\
\hline & & & & Monológico (-) \\
\hline & & \multirow[b]{2}{*}{ POESIA } & \multirow[b]{2}{*}{ Centripeta } & Monológico (+) \\
\hline & & & & $\begin{array}{l}\text { Dialógico } \\
\text { (polifonia) }(-)\end{array}$ \\
\hline
\end{tabular}

Fig. 1 - Os gêneros discursivos literários em Bakhtin

Fonte: elaboração do autor

Essa junção irá incidir na intensificação, no romance hiper-regional, do caráter polifônico e plurilinguístico. Para exemplificar essa junção da poesia no texto romanesco, percebemos que ela se encontra permeada nas narrativas (em análise) de Rosa e Saramago através dos gêneros da literatura oral popular (expressões populares, provérbios e romanceiros populares). O romanceiro popular aparecerá tanto na transcrição (literal ou parodeada) das modalidades poéticas populares (quadras, cantigas etc.) quanto na referência a personagens típicas das narrativas medievais de cavalaria, tal como nos exemplos:

\footnotetext{
Naqueles dias ele andava de pé-no-chão, mais com uma calça apertada nas canelas e encurtada, e mesmo muito esmolambado na camisa. (...) Nem eu no achar mais que ele era o ferrabrás [grifo nosso]? (ROSA, 2001, p. 250).

Vão a trote, a galope, bate-lhes o sol nas armaduras, fraldejam as gualdrapas nos joelhos das bestas, ó cavalaria, ó Roldão, Oliveiros e Ferrabrás [grifo nosso], ditosa pátria que tais filhos pariu. (SARAMAGO, 2012, p. 35).
}

O redemoinho narrativo também se constrói pela oscilação do foco narrativo; e, para visualizarmos melhor esse processo, apropriei-me da tipologia de Gérard Genette e de Norman Friedman. Assim, nas categorias narrativas de Genette, percebe-se que, nos romances hiperregionais, existirá uma oscilação da narração tanto em um nível intradiegético quanto extradiegético. No intradiegético, haverá uma alternância entre a dimensão autodiegética (narração em $1^{a}$.pessoa) e a heterodiegética (narração em $3^{a}$.pessoa), tal como observamos nos seguintes trechos de Rosa e Saramago:

E por aí eu mesmo mais acalmado ri, me ri [grifo nosso], ele era engraçado. Naquele tempo, também, eu não tinha tanto o estrito e precisão, nestes assuntos. E o Jõe contava casos. Contou [grifo nosso]. Caso que se passou no sertão jequitinhão, no arraial de São João Leão, perto da terra dele, Jõe. Caso de Maria Mutema e do Padre Ponte. 
Naquele lugar existia uma mulher [grifo nosso], por nome Maria Mutema, pessoa igual às outras, sem nenhuma diversidade. (ROSA, 2001, p. 237-238)

Diz o outro. Eu estava [grifo nosso] com uns copos e disse isso, mas tu não me tinhas dito nada, a verdade é só essa. Disse o José Gato [grifo nosso], muito sereno. Então anda lá cem passos para diante, assim que apanhou o outro a jeitos de não o matar, trás, trás, manda-lhe duas carapinhadas ao espinhaço, só para ficarem entre a pele alguns e os outros espirrarem para trás, não era para matar, deu-lhe duas verdascadas que aventou com ele abaixo, É para saberes que te portas como um homem, que aqui não se trata de rapazices. Ao José Gato conheci-o [grifo nosso] sempre como um homem que se meteu naquela vida porque não ganhava para comer. Chegou a andar por aqui, era en gaiato pequeno [grifo nosso]." (SARAMAGO, 2012, p. 134).

No primeiro exemplo retirado de Grande sertão, Riobaldo empresta a sua voz (foco narrativo em $1^{\text {a }}$.pessoa) para Jõe Bexiguento que narra em $3^{a}$. pessoa. Já, o(s) narrador(es) de Saramago, em Levantado do Chão, utiliza(m), como pontuação, somente vírgulas e pontos. Essa utilização restrita da pontuação, na narrativa, provoca um imbricamento do discurso direto no indireto fazendo com que haja a quebra de uma delimitação entre o discurso direto (em $1^{a}$.pessoa) e o indireto ( $3^{\mathrm{a}}$.pessoa).

No extradiegético, nas narrativas hiper-regionais, através da "narração onisciente intrusa" e "narração-câmera" (classificações propostas por Friedman) percebemos também um descentramento bastante interessante na narração. $\mathrm{Na}$ "intrusa" temos um narrador onisciente que interrompe a narração dos fatos do enredo (geralmente, de forma irônica), para emitir julgamentos de valor através de interpelações ao leitor. Como exemplo, temos:

Hem? Hem? [grifo nosso] O que mais penso, testo e explico: todo-o- mundo é louco. O senhor, eu, nós, as pessoas todas. Por isso é que se carece principalmente de religião: para se desendoidecer, desdoidar. Reza é que sara da loucura. No geral. Isso é que é a salvação-da-alma... Muita religião, seu moço![grifo nosso] Eu cá, não perco ocasião de religião. Aproveito de todas. Bebo água de todo rio... Uma só, para mim é pouca, talvez não me chegue. (ROSA, 2001, p.32).

"Quando, uns anos mais tarde, trouxeram João Mau-Tempo para Lisboa por motivos que logo saberemos, já Sara da Conceição se finara, rodeada pelo riso das enfermeiras, a quem a pobre tonta, humildemente, pedia uma garrafa de vinho, imagine-se, para um trabalho que tinha de acabar antes que se fizesse tarde. Que dor de coração, senhoras e cavalheiros [grifo nosso]." (SARAMAGO, 2012, p. 113).

Já na narração-câmera, temos um modo narrativo que cumpre o papel de um observador imparcial (de forma contrária ao "incluso"), influenciado pelas técnicas narrativas cinematográficas. Nesse foco narrativo temos uma "visão de fora" que lembra a visão de um "câmera-man" ao deslocar as lentes de sua máquina cinematográfica.

Aí lá cheio o curralão, com a boa animalada nossa, os pobres dos cavalos ali presos, tão sadios todos, que não tinham culpa de nada; e eles, cães aqueles, [...] fazendo fogo! [...] os cavalos desesperaram em roda, sacolejados esgalopeando, uns saltavam erguidos em chaça, as mãos cascantes, se deitando uns nos outros, retombados no enrolar dum rolo, que reboldeou, batendo com uma porção de cabeças no ar, os pescoços, e as crinas sacudidas esticadas, espinhosas: eles eram só umas curvas retorcidas! (ROSA, 2001, p. 355).

"Tomemos esta formiga, melhor, consideremo-la apenas por ser uma das maiores e levantar a cabeça como os cães, vai agora rente à parede em récua com as suas irmãs, terá tempo de fazer dez vezes a sua comprida viagem (...) Agora mesmo caiu um dos homens, fica ao nível das formigas (SARAMAGO, 2012, p. 169).

Esse efeito oscilante também será adornado por alguns processos neobarrocos que ocorrem na linguagem. Segundo o poeta e estudioso cubano Severo Sarduy, os processos

Revista do GELNE, Natal/RN, Vol. 20 - Número 1: p. 285-295. 2018 
principais seriam: a "substituição", a "proliferação" e a "condensação" (cf. DRUMOND, 2008, p. 134).

$\mathrm{Na}$ "substituição" temos a troca do significante por outro de natureza ou campo semântico diverso, instaurando a esse novo termo, dentro do discurso, um alto grau metafórico. Como exemplificação desse processo, podemos observar os seguintes termos e expressões lexicais em Rosa e Saramago: “...os olhos de nem ser - se viu -; e com máscara de cachorro [grifo nosso]” (ROSA, 2001, p.23); “...entra-lhe um podengo pela porta dentro,...tem duas pernas e nome de homem, mas é bicho de morder, e diz, Trago aqui um papel para vocemecê assinar...."(SARAMAGO, 2012, p. 90).

Já na "proliferação" temos a obliteração de um determinado significado de um significante, todavia sem substituí-lo tem-se a introdução de uma cadeia de significantes que se une em uma relação metonímica; e isso faz com que esse conjunto de termos estabeleça o significante (que pode ou não estar ausente do enunciado) através da reconstrução dele em uma leitura radial. Esse processo é percebido de maneira semelhante tanto em Rosa quanto em Saramago, nos seguintes trechos:

\footnotetext{
Arres, me deixe lá, que - em endemoninhamento ou com encosto - o senhor mesmo deverá de ter conhecido diversos, homens, mulheres. Pois não sim? Por mim, tantos vi, que aprendi. Rincha-Mãe, Sangue-d'Outro , o Muitos-Beiços, o Rasga-em-Baixo, Faca-Fria, o Fancho-Bode, um Treciziano, o Azinhavre... o Hermógenes... [grifo nosso] Deles, punhadão. (ROSA, 2001, p.25-26).

...as pessoas da cidade cuidam, em sua ignorância, que tudo é semear e colher, pois muito enganadas vivem se não aprenderem a dizer as palavras todas e a entender o que elas são, ceifar, carregar molhos, gadanhar, debulhar à máquina ou a sangue, malhar o centeio, tapar palheiro, enfardar a palha ou ofeno [grifo nosso]... (SARAMAGO, 2012, p. 89).
}

E na "condensação" temos a fusão ou permutação do intercâmbio entre significantes juntamente com seus significados envolvendo vários elementos (fonéticos, plásticos etc.) pertinentes ao universo semântico de cada um dos dois termos. Assim, dessa fusão, será gerado um terceiro termo lexical bem mais expressivo. Como ilustração desse processo que ocorre em diversos trechos do discurso hiper-regional das supracitadas obras de Rosa e Saramago temos: "As exalastrava [grifo nosso] a distância, adiante, um amarelo vapor..." (ROSA, 2001, p. 64) que poderíamos apontar um significante elaborado a partir da fusão de dois verbos - exalar e alastrar, e "...Sara, enquerençada [grifo nosso] ao ponto de jurar que se não casasse com Domingos MauTempo, não casaria com ninguém.” (SARAMAGO, 2012, p. 23) - provável junção do verbo enqueixar com o substantivo querença (ou de sua forma adjetivada por sufixo querençada).

Contudo, diante desses processos linguísticos "neobarrocos" teremos também uma estrutura de gêneros distinta a qual denominaremos de "matrioska" por seu caráter de "encaixe" e "nuclear" que analisaremos no próximo tópico.

\section{O colorido da “estrutura matrioska" nos romances de Rosa e Saramago}

O desenvolvimento dessa estrutura narrativa que denominei de "matrioska" ocorreu da necessidade de encontrar um aporte teórico que conseguisse descrever as especificidades da estrutura hiper-regional. Embora a "teoria do autoencaixe" (de Tzvetan Todorov) se aproxime da estrutura verificada nos romances de Rosa e Saramago, não podemos usá-la, pois não possui a consciência de uma última estrutura nuclear encaixada na narrativa.

Nas estruturas dos romances hiper-regionais analisados, percebemos três matrioskas (ou gêneros) principais assimilados: a narrativa memorialista e confessional; a epopeia mítica cavalariana; o texto dramatúrgico.

$\mathrm{Na}$ matrioska da narrativa memorialista e confessional tem-se uma mescla, na fala dos narradores, das tintas autobiográficas do autor. Isso estará presente tanto na narrativa de Rosa

Revista do GELNE, Natal/RN, Vol. 20 - Número 1: p. 285-295. 2018 
quanto na de Saramago. $\mathrm{Na}$ "contação" de Riobaldo, irão se confundir vários aspectos memorialísticos e autobiográficos vivenciados pelo próprio Rosa no interior de Minas Gerais, nas imediações de Cordisburgo, cidade natal do escritor que se situa na área norte do estado de Minas Gerais (WARD, 1987, p.83-84). É provável que alguns dos "causos" paralelos relatados em Grande sertão: veredas tenham lhe sido narrados por alguns contadores de histórias ou vaqueiros, tal como atesta a história do Burrinho Pedrês em Sagarana (LEITE, 2000, p.55-56), na qual Rosa teve acesso quando tinha apenas nove anos de idade, chegando a conhecer o verdadeiro protagonista da história.

Em Saramago, temos esse reaproveitamento das tintas biográficas até mesmo pelo fato do épico Levantado do Chão ser a saga da humilde família alentejana Mau-Tempo, que, destarte, faz lembrar o contexto da infância e adolescência de Saramago, provindo de uma família camponesa em Azinhaga (Concelho de Golegã) na região de Alentejo. Essa obra de Saramago perpassa tanto uma memória individual quanto coletiva na medida em que, situando as dores da exploração e sofrimentos dos camponeses, perpassa o final do século XIX e a primeira metade do século XX (dentro do contexto das duas grandes guerras mundiais). Isso irá traduzir-se em uma "metaficção histórica" (como observa Linda Hutcheon) definida como uma das características das narrativas contemporâneas que têm, na busca de um auto-conhecimento da história e da ficção, uma atividade humana que repensa e reconstrói as formas e conteúdos do passado dando voz àquele que foi ignorado (ou marginalizado) pela historiografia oficial.

Com a matrioska da epopeia mitica cavalariana, temos um fator bem recorrente nessa estética, a introdução da matéria épica das cavalarias medievais. É interessante percebermos o porquê da apropriação dessa matéria das epopeias nas narrativas contemporâneas do final do século XX e início do século XXI. O primeiro ponto é que, até mesmo pela etimologia de epopeia (combinação do substantivo grego "épos" - significando "aquilo que é expresso pela fala" - com o verbo "poïen" - "fazer, fabricar"), temos uma relação mais íntima com a oralidade e da própria presença da poesia permeando a narrativa; e, como segundo ponto, o estabelecimento da facilidade de encaixe com o jogo teatral (última matrioska que falaremos em seguida), visto que o oral (dentro de suas diversas marcações performáticas) cobrará uma corporeidade típica dos textos dramatúrgicos. Isso tudo, servindo a construção de uma ambientação mítica que não irá mascarar as diferenças ou alienar o leitor, mas (pelo contrário) possibilitará essa transfiguração do real, resgatando a autoestima e a identidade dos desvalidos e marginalizados.

Em Rosa, o épico não se dará pela forma (nem mesmo parodiada), mas pela "matéria épica" manifestada através do mítico e das narrativas dos "livros de cavalaria" que, nos romance de ambos autores, entrarão através da influência do romanceiro e dos mitos populares.

Já em Saramago, o épico será construído com uma função ambígua, tanto para fundir os tempos históricos do passado medieval com o presente da narrativa com o objetivo de mostrar o processo histórico da exploração e sujeição dos camponeses (antigos servos das glebas dos senhores feudais); quanto para resgatar a autoestima da família Mau-Tempo (e, por extensão de todo ser marginalizado) dentro de uma linhagem nobre e de participação fundamental na história.

Mas João Mau-Tempo, só mais tarde se virá a saber, é filho de rei e único herdeiro do trono, real, real [grifo nosso], por João Mau-Tempo rei de Portugal, aí encosta o barco ao pontão, quem ia adormecido acordou, e quando o preso dá por si estão dois homens na sua frente, Então é só este, perguntam, e aquele que veio de acompanhante responde, Desta vez não há mais. (SARAMAGO, 2012, p.240).

Por fim, a matrioska do texto dramatúrgico que, segundo o que percebemos, embora seja o gênero composicional mais discreto dentro da estrutura romanesca hiper-regional, apresenta-se como um núcleo fundante pelo qual a narrativa dentro dessa estética se constitui de maneira mais vibrante e penetrante nos leitores. No entanto, a construção dessa matrioska segue, conforme a teoria da performance de Paul Zumthor nos textos poéticos e narrativos, cumprindo três etapas: a primeira seria o estabelecimento do romance como a fôrma principal da narrativa; o segundo

Revista do GELNE, Natal/RN, Vol. 20 - Número 1: p. 285-295. 2018 
consiste em permear a narrativa de vocalidade e corporeidade obtidos, na estética literária hiperregional, sobretudo por meio do "narrador-intruso", da matéria poética (como também épica) permeando a narrativa, além do formulismo (típico dos ditados populares e provérbios); e, na terceira fase, a presença de marcas que lembram as rubricas teatrais (indicações de dicção, intensidade vocal e posicionamento espacial).

Como exemplificação disso, temos alguns dos diversos trechos que permeiam a narrativa de Rosa e Saramago:

De tudo. E ele, vendo o que via, perguntou aonde se ia, dando dizendo de querer ir junto. - "Bobou?" - foi só o que Medeiro Vaz indeferiu. -Bobei, chefe. Perdão peço..." - Jõe Engrácio reverenciou. Medeiro Vaz não era carrancista. Somente de mais sisudez, a praxe, homem baseado. Às vezes vinha falando surdo, de resmão [grifo nosso]. Com ele, ninguém vereava. De estado calado, ele sempre aceitava todo bom e justo conselho. (ROSA, 2001, p. 59-60).

...e em Alcântara encontraremos um grupo de homens a trabalhar nas linhas do caminho de ferro, e eles disseram, Eh, saloios, já é cisma, por isso o nosso cunhado deu sorte e foi discutir com eles, repita lá isso, houve sopapos, mas depois fugiremos corridos de vergonha, e os outros a gritar, Olha o da jaqueta [grifo nosso], Olha o saloio, quando nós não somos saloios, e que fôssemos, não seria desprezo nenhum. Tornaremos a atravessar o rio, que grande mar, e um senhor que vai no barco diz com muito bom modo, Isto aqui é o Tejo, o mar é além, $e$ apontou [grifo nosso], e então é que reparamos, não se via terra, será possível. (SARAMAGO, 2012, p.78-79).

E, para compreendermos, a que fim servirá o "redemoinho narrativo" e a "estrutura matrioska", teremos que perceber que esses dois processos estarão imbuídos na construção de uma cronotopia hiper-regional (pautando-se na percepção bakhtiniana) que terá o cronotopo do Sertão como eixo imagético principal.

\section{O cronotopo do SERTÃO na paisagem mineira de Rosa e alentejana de Saramago}

O primeiro ponto fundamental é definir, para Bakhtin, em que consiste a cronotopia. Segundo Bakhtin (1998, p.211), ela é conceituada como a "interligação fundamental das relações temporais e espaciais, artisticamente assimiladas em literatura", ou mesmo "como uma categoria conteudístico-formal da literatura". Nessa análise, não podemos perder de vista que cada povo possui uma maneira própria de conceber o tempo e o espaço, por exemplo, para alguns povos o tempo será "cíclico"; para outros ele seguirá em uma "linearidade irreversível". Seguindo na compreensão de cronotopia de Bakhtin (1998, p.212), expressa em seu livro Questões de Literatura e Estética: teoria do romance, chegamos à construção de um cronotopo do Sertão, isto é, o espaço aglutinador da cronotopia hiper-regional.

Com relação às características dessa cronotopia nos baseamos em dois tipos de cronotopia apontadas por Bakhtin: a dos romances biográficos e a das novelas (ou romances) de cavalaria. Assim, como características dessa cronotopia do romance hiper-regional, teremos uma narrativa dentro de uma perspectiva "mítico-real" associada a um "eixo temporal verticalizado" sobrepondo fases e períodos históricos (contribuição da cronotopia do romance de cavalaria); além disso, (considerando a contribuição da cronotopia do romance biográfico) iremos ter o aspecto da "tomada de consciência do eterno-devir" desses "narradores-nação" (ou "narradoresrio" como Willi Bolle chamou o Riobaldo de Guimarães Rosa) dentro da perspectiva de narrativas, calcadas na "fragmentação da memória". Isso irá perfazer um caminho identitário não só dos narradores, mas da própria nação brasileira e portuguesa dentro da perspectiva do "bildungsroman" (os romances de formação).

Este foi um caso. Estivesse o João Brandão nesta volta, seria assim, não seria, quis-me com o José Gato, com outro não tenho a certeza. Mais tarde a quadrilha mudou-se para 
a zona de Vale de Reis, quem é da cidade não imagina os sertões que por aí há [grifo nosso]. Eram umas grutas, umas covas nuns brejos malignos, quem é que se atrevia a chegar-se para aquelas bandas, nem a guarda, a guarda não se habilitava. (SARAMAGO, 2012, p. 129).

O senhor tolere, isto é o sertão. Uns querem que não seja: que situado sertão é por os campos-gerais a fora a dentro, eles dizem, fim de rumo, terras altas, demais do Urucuia. Toleima. (...) O gerais corre em volta. Esses gerais são sem tamanho. Enfim, cada um o que quer aprova, o senhor sabe: pão ou pães, é questão de opiniães... O sertão está em toda a parte [grifo nosso]. (ROSA, 2001, p. 23-24).

Esse cronotopo do Sertão, no entanto, na cronotopia do romance hiper-regional, não servirá como reforçador de estereótipos ou fetiches, mas será percebido como a própria metáfora do cérebro e do inconsciente humano. Por isso, a construção mais frequente do Sertão será a da sua ligação com o labirinto.

O espaço do labirinto foi desenvolvido, na literatura, a partir do mito grego do Minotauro e do labirinto construído no palácio cretense de Minos para esconder o monstro mítico. Conforme Jean Chevalier (2007, p.530-532), o labirinto possui também dimensões mais amplas referindo-se, essencialmente, a um "entrecruzamento de caminhos", onde o neófito de conhecimentos internos deve realizar uma "viagem iniciática" para atingir o centro do labirinto e encontrar o grande tesouro espiritual que será o domínio e conhecimento de si mesmo. E, dentro ainda da doutrina ascético-mística, o labirinto apresentará a conotação de infinitude, onde as idas e voltas dentro desse labirinto também representam, paradoxalmente, a morte e a ressurreição espiritual. Sabendo que o labirinto também traz uma dimensão barroca (ou neobarroca) tanto na literatura europeia contemporânea quanto na latinoamericana, conforme aponta Sant'Anna (2000, p.72-73).

$\mathrm{Na}$ Europa, esse surgimento do labirinto na literatura prefigura em nomes como Joyce e o seu labirinto linguístico, Proust com o labirinto temporal, Ionesco com o labirinto non sense, Beckett com o labirinto do absurdo. A diferença fundante entre o labirinto desenvolvido na literatura europeia para o da literatura latinoamericana é que naquela (a europeia) o centro do labirinto é um grande vazio (SANT'ANNA, 2000, p.73); e na literatura latinoamericana esse centro será a busca identitária que perpassa a discussão histórica e metafísico-existencial.

Com isso, percebemos que a chave para entendermos o projeto transfigurador da literatura produzida por Guimarães Rosa e José Saramago perpassam a forma labiríntica desenvolvida no cronotopo do Sertão.

a) O Labirinto do Grande sertão: veredas

A construção do labirinto, em Rosa, também contém a presença de rios que recortam esse Sertão, tal como aponta o subtítulo "veredas" (cf. ARRIGUCCI JÚNIOR, 1994, p.23); enquanto que Bolle (2004, p.86) nos adverte que esse labirinto refere-se também ao cérebro humano sendo uma "metáfora da aprendizagem", onde se perder (ou permitir-se) é tão importante quanto encontrar o caminho. Assim, em um "retrato criptografado do Brasil", temos, no labirinto roseano, a construção do labirinto do espaço-mítico pelo labirinto das palavras de Riobaldo (ou seja, um labirinto dentro de outro labirinto) guiando seu interlocutor/leitor no movimento errante pelo Grande Sertão.

\section{b) O Labirinto de Levantado do Chão}

A construção do labirinto, em Saramago, é feita pelas paisagens que seu(s) narrador(es) descreve $(\mathrm{m})$ tanto do contexto rural quanto do urbano tendo o "CHÃO" como o elemento principal dos deslocamentos da família Mau-Tempo que ora percorrem os espaços lusitanos, ora os espaços de outros países (as viagens de António Mau-Tempo, último primogênito da prole, que chega a atingir também as terras francesas em seus tráfegos migratórios). 
O que mais há na terra, é paisagem. Por muito que do resto lhe falte, a paisagem sempre sobrou, abundância que só por milagre infatigável se explica, porquanto a paisagem é sem dúvida anterior ao homem, e apesar disso, de tanto existir, não se acabou ainda. Será porque constantemente muda: tem épocas no ano em que o chão é verde, outras amarelo, e depois castanho, ou negro. E também vermelho, em lugares, que é cor de barro ou sangue sangrado. (SARAMAGO, 2012, p. 11).

\section{CONSIDERAÇÕES FINAIS}

Essa é a parte mais ingrata de todo esse trabalho, pois como pode se fechar algo que está em constante movimento e em um "eterno-devir". A literatura como arte é uma "obra aberta", no dizer de Umberto Eco, onde os leitores imersos em momentos lúdicos e prazerosos irão compor-lhe os sentidos. Contudo, depois de todo esse percurso pelo hiper-regional percebemos que Grande sertão: veredas e Levantado do Chão não são obras fáceis. $\mathrm{Na}$ verdade, são monumentais enigmas a nos fitar e interpelar; mas, se não soubermos decifrar, seremos devorados pela nossa própria ignorância, por isso temos que ajustar nossas lentes tal como nos orienta Proust; e nos tornarmos sagazes detetives na interpretação das pistas discursivas dentro do "cronotopo" do Sertão mítico e onírico construído por Rosa e Suassuna. No entanto, se pudéssemos resumir a função precípua da literatura em apenas uma única palavra, ela seria: Transfiguração.

E, tendo por leme principal essa finalidade, a estética hiper-regional irá propor, partindo inicialmente do local (e regional), atingir as dores, os sonhos e as descobertas universais da humanidade, ajudando a abrirmo-nos ao mundo diverso e singular do "outro" sem medo, arrogância, ou mesmo, violência física ou simbólica do preconceito.

\section{REFERÊNCIAS BIBLIOGRÁFICAS}

ARRIGUCCI JÚNIOR, Davi. O mundo misturado. In: Revista Novos Estudos - Cebrap, no 40, São Paulo, novembro de 1994, p. 7-29.

BAKHTIN, Mikhail. Questões de literatura e estética: a Teoria do Romance. Trad. de Aurora Fornoni Bernadini et al. 4.ed. São Paulo: Editora UNESP; HUCITEC, 1998.

BOLLE, Willi. Grandesertão.br: o romance de formação do Brasil. São Paulo: Duas Cidades; Ed.34, 2004. (Espírito Crítico)

CALLADO, Antonio et al. Depoimentos sobre João Guimarães Rosa e sua Obra. Rio de Janeiro: Nova Fronteira, 2011.

CAMPOS, Haroldo de. Ruptura dos gêneros na Literatura Latino-Americana. São Paulo: Editora Perspectiva, 1977.

CANDIDO, Antonio. Literatura e subdesenvolvimento. In: . A Educação pela noite e outros ensaios. São Paulo, Ática, 1989. p. 140-162.

CHEVALIER, Jean. Dicionário de simbolos: (mitos, sonhos, costumes, gestos, formas, figuras, cores, números) / Jean Chevalier, Alain Gheerbrant, com a colaboração de: André Barbault...[et al.]; coordenação Carlos Sussekind; tradução Vera da Costa e Silva...[et al.]. 21. ed. Rio de Janeiro: José Olympio, 2007 
DRUMOND, Josina Nunes. As dobras do sertão: palavra e imagem. O neobarroco em Grande Sertão: Veredas, de Guimarães Rosa e em imagens do Grande Sertão, de Arlindo Daibert. São Paulo: Annablume, 2008.

HUTCHEON, Linda. Poética do pós-modernismo: história, teoria, ficção./ Linda Hutcheon; tradução Ricardo Cruz. Rio de Janeiro: Imago Ed., 1991. (Logoteca).

LEITE, Ascendino. Ascendino Leite entrevista Guimarães Rosa. 2. ed. Sônia Maria van Dijck Lima (Org.). João Pessoa: Editora Universitária/ UFPB, 2000.

LIPOVETSKY, Gilles. A cultura-mundo: resposta a uma sociedade desorientada. Gilles Lipovetsky e Jean Serroy. Tradução de Maria Lucia Machado. São Paulo: Companhia das Letras, 2011.

MAFFESOLI, Michel. Sobre o nomadismo: vagabundagens pós-modernas. Tradução de Marcos de Castro. Rio de Janeiro: Record, 2001.

ROSA, João Guimarães. Grande sertão: veredas. 19. ed. Rio de Janeiro: Nova Fronteira, 2001.

SANT'ANNA, Affonso Romano de. Barroco: do quadrado à elipse. Rio de Janeiro: Rocco, 2000.

SARAMAGO, José. Levantado do chão. 17. ed. Rio de Janeiro: Bertrand Brasil, 2012.

SCARPELLI, Marli Fantini. Heterogeneidade, transculturação, hibridismo: a terceira margem da cultura latino-americana. In.: CHAVES, Rita et al. Literaturas em movimento: hibridismo cultural e exercício crítico. Rita Chaves e Tânia Macêdo (orgs.). São Paulo: Arte \& Ciência, 2003. (Via Atlântica, 5). p.51-65.

WARD, Teresinha Souto. O discurso oral em Grande Sertão: Veredas. São Paulo: Duas Cidades; [Brasília]: INL, Fundação Nacional Pró-Memória, 1984.

ZUMTHOR, Paul. Introdução à poesia oral. Tradução de Jerusa Pires Ferreira; Maria Lúcia Diniz Pochat; Maria Inês de Almeida. São Paulo: Hucitec, 1997. 